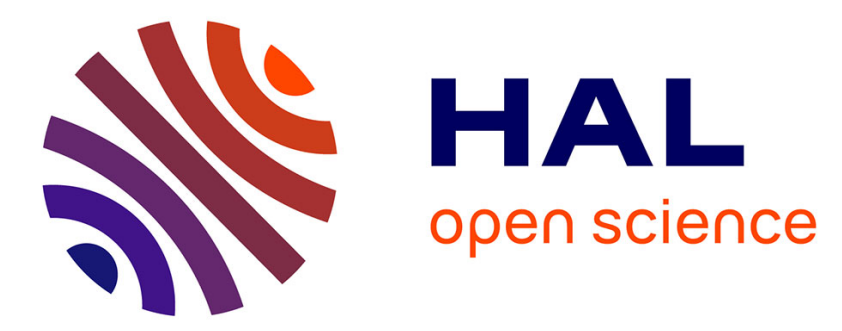

\title{
Photoionization of LinHm clusters
}

B. Vezin, P. Rambaldi, Ph. Dugourd, M. Broyer

\section{To cite this version:}

B. Vezin, P. Rambaldi, Ph. Dugourd, M. Broyer. Photoionization of LinHm clusters. Journal de Physique IV Proceedings, 1994, 04 (C4), pp.C4-651-C4-654. 10.1051/jp4:19944173 . jpa-00252631

\section{HAL Id: jpa-00252631 https://hal.science/jpa-00252631}

Submitted on 1 Jan 1994

HAL is a multi-disciplinary open access archive for the deposit and dissemination of scientific research documents, whether they are published or not. The documents may come from teaching and research institutions in France or abroad, or from public or private research centers.
L'archive ouverte pluridisciplinaire HAL, est destinée au dépôt et à la diffusion de documents scientifiques de niveau recherche, publiés ou non, émanant des établissements d'enseignement et de recherche français ou étrangers, des laboratoires publics ou privés. 


\title{
Photoionization of $\mathrm{Li}_{n} \mathrm{H}_{m}$ clusters
}

\author{
B. VEZIN, P. RAMBALDI, Ph. DUGOURD and M. BROYER
}

Laboratoire de Spectrométrie Ionique et Moléculaire, URA 171 du CNRS, Université Lyon I, Bât. 205, 43 Bd du 11 Novembre 1918, 69622 Villeurbanne cedex, France

\begin{abstract}
Ionization potentials of $\mathrm{Li}_{\mathfrak{n}} \mathrm{H}_{\mathrm{m}}$ clusters have been measured from bare $\mathrm{Li}_{\mathrm{n}}$ clusters to hydrogen saturated clusters. The evolution of electronic properties with the number of $\mathrm{H}$ is discussed. We found that $\mathrm{Li}_{\mathrm{n}} \mathrm{H}_{\mathrm{m}}$ clusters behave like $\mathrm{Li}_{\mathfrak{n}-\mathrm{m}}$ clusters. This similarity may be due to a segregation between a metallic part and an insulator part inside the cluster.
\end{abstract}

\section{Introduction}

Alkail metal are among the most studied clusters, from both experimental and theoretical point of view. They are the prototypes of smail metallic particles and they are well described by the jellium model. For a few years, scientists are interested in alkali halyde clusters. In the bulk, these systems are salts with a $\mathrm{NaCl}$ structure and ionic bounds. For stoechiometric clusters, the cohesion is dominated by electrostatic forces and they have the bulk structure which make calculations easier. Numerous experimental results have been obtained on $\mathrm{Na}_{n} \mathrm{Cl}_{n-1}+$ (or $\mathrm{Na}_{n-1} \mathrm{Cl}_{n^{-}}$) and $\mathrm{Na}_{n} \mathrm{~F}_{n-1} 1^{+}$(or $\mathrm{Na}_{n-1} \mathrm{~F}_{n}{ }^{*}$ ) clusters (see for examples Ref. $[1,2])$. A stoechiometric cluster is an insulator whereas, in a bare metal clusters valence electrons are delocalized. A significant transition of electronic properties and of the structure is expected when the proportion of metal atoms increases in the cluster. However little is known about clusters with intermediate composing. Does a gradual attenuation of the metallic character occur in all the cluster volume, or does a segregation between a metallic part and an insulator appear inside the cluster ?

Due to their little number of electrons, $\mathrm{Li}_{n} \mathrm{H}_{\mathrm{m}}$ clusters appear to be the ideal system to study this evolution : it is the mixed system the most accessible to calculations. Moreover, it allows to investigate the bounding of an hydogen atom with a metal and chimisorption of hydrogen on metal surfaces. In recent papers $[3,4]$ we published the first results on $\mathrm{Li}_{n} \mathrm{H}$ and $\mathrm{Li}_{n} \mathrm{H}_{2}$ clusters. By varying nucleation conditions, we managed to produce $\mathrm{Li}_{n} \mathrm{H}_{m}$ from 0 hydrogen atom to hydrogen saturated clusters. We present in this paper the ionization potentials of $\mathrm{Li}_{n} \mathrm{H}_{m}$ clusters $3 \leq n \leq 11$ and $0 \leq m \leq 6$. These I.P.s are mainly dominated by the number of valence electrons. Evolution of electronic properties from pure metal clusters to stoechiometric cluster is discussed and compared with results on $\mathrm{NaCl}$ and $\mathrm{NaF}$ clusters.

\section{Experiment}

Hydrogenated clusters were produced in a seeded molecular beam by coexpansion of 10-100 mbars of lithium vapor and $1-5$ bars of a mixture of Argon and Hydrogen. For this experiment we used pure isotopic ${ }^{7} \mathrm{Li}$ lithium (purity $>99.88 \%$ ). It avoids superposition of peaks such as ${ }^{7} \mathrm{Li}_{\mathrm{n}-1}{ }^{6 \mathrm{LiH}}$ and ${ }^{7} \mathrm{Li}_{\mathbf{n}}$ which have the same mass [3]. This allows us to measure precisely the intensity of $\mathrm{Li}_{n} \mathrm{H}_{m}$ clusters with more than 2 hydrogen atoms. Moreover, we are able to vary the proportion of hydrogen in the carrier gaz from $0 \%$ to $15 \%$ and so to favorize clusters with few 
hydrogen atoms or, in the other hand, hydrogen saturated clusters. The clusters were ionized by mean of an $\mathrm{XeCl}$ excimer pumped tunable dye laser and the required UV range was obtained by frequency doubling using either a BBO crystal (from $220 \mathrm{~nm}$ to $270 \mathrm{~nm}$ ) or a KDP crystal (from 270 to $330 \mathrm{~nm}$ ). Ions were collected and mass analyzed through a time of flight mass spectrometer.
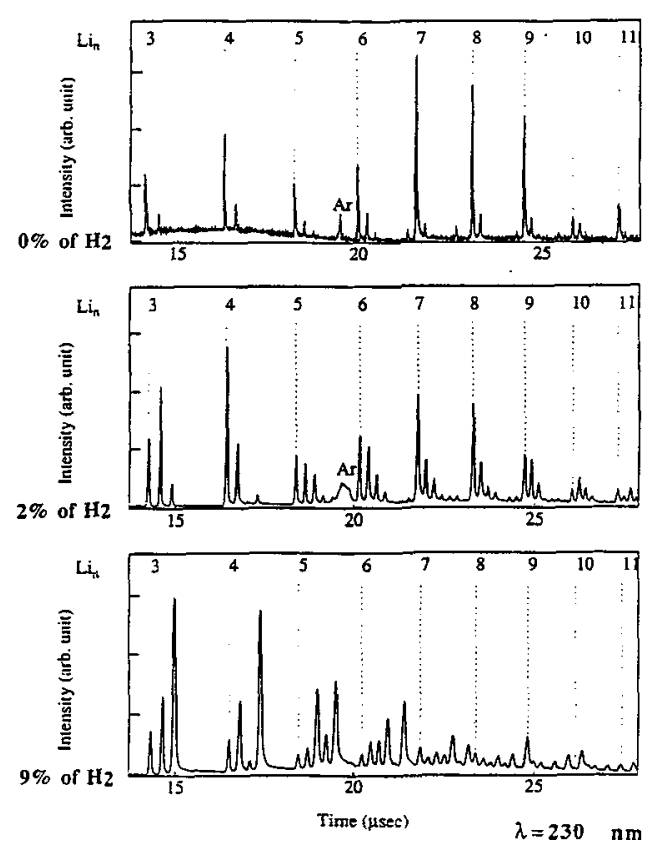

Figure 1 : mass spectra of photoionized $\mathrm{Li}_{n} \mathrm{H}_{m}$ clusters. They were recorded with 3 different $\mathrm{H}_{2}$ percentages in the carrier gaz a) $0 \%$ b) $2 \%$ c) $9 \%$.

\section{Results and discussion}

Figure 1 shows 3 mass spectra recorded with a photon energy of $5.4 \mathrm{eV}$, with a low power $\left(\approx 1 \mathrm{~mJ} / \mathrm{cm}^{2}\right.$ ). First spectrum has been obtained with no hydrogen in the carrier gaz. Main peaks correspond to the $\mathrm{Li}_{n}$ clusters. To the right of these peaks, the weak peaks are due to $\mathrm{Li}_{n} \mathrm{H}$ clusters (there were traces of hydrogen and water in the experiment). When $2 \%$ of $\mathrm{H}_{2}$ is added to the carrier gaz, clusters with 1 and 2 hydrogens are observed to the right of the main peaks. One can notice the particulary high intensity of the $\mathrm{LigH}^{+}$peak. The last spectrum has been recorded with $9 \%$ of $\mathrm{H}_{2}$. The most intense peaks correspond to $(\mathrm{LiH})_{n} \mathrm{Li}^{+}$. These ionic species are saturated in hydrogen, no valence electron remains free. For clusters with less hydrogen, intensities alternation in respect of valence electrons number (n-m) is striking. Ionic clusters with an even number of valence electrons are the more intense. This is due to electronic pairing effects. High intensity of $\mathrm{Li}_{\mathbf{n}} \mathrm{H}_{\mathbf{n}-1}{ }^{+}$species is similar to what have been observed for other mixed clusters. CsO [5] and LiO [6] clusters are saturated in oxygen for a number of oxygen equal to half the number of metal atoms (due to the valence 2 of oxygen). Concerning the alkali halyde, only $\mathrm{Na}_{\mathfrak{n}} \mathrm{Cl}_{\mathrm{n}-1} 1^{+}$(or $\mathrm{Na}_{\mathrm{n}-1} \mathrm{Cl}_{\mathrm{n}}{ }^{-}$) and $\mathrm{Na}_{\mathbf{n}} \mathrm{F}_{\mathrm{n}-\mathrm{I}^{+}}$ (or Nan-1 $F_{n}{ }^{-}$) clusters ions are observed $[1,2]$, in most experimental conditions.

There are two major differences between our results and $\mathrm{NaCl}$ or $\mathrm{NaF}$ spectra. First, we are able to produce non stoechiometric clusters. Second, some $\mathrm{Na}_{n} \mathrm{Cl}_{n-1}{ }^{+}$and $\mathrm{Na}_{n} \mathrm{~F}_{\mathrm{n}-1^{+}}$clusters present very high intensities for $\mathrm{n}=2,4,6,8,12$, $15,18 \ldots$, these clusters have a cuboid structure (little cuboid piece of the bulk). On our spectra, we observe no magic number for any $\mathrm{Lin}_{n} \mathrm{H}_{\mathbf{n}-1^{+}}$ clusters, even using a very low photon energy.

We recorded mass spectra (with different $\mathrm{H}_{2}$ percentages) varying the wavelength of the ionizing laser from $220 \mathrm{~nm}$ to $400 \mathrm{~nm}$. For each wavelengh, we checked that no multiphotonic processes took place. Then we obtained 


\begin{tabular}{|c|c|c|c|c|c|c|c|}
\hline$n$ & $\mathrm{Li}_{n}$ & $\mathrm{Li}_{n} \mathrm{H}$ & $\mathrm{Li}_{n} \mathrm{H}_{2}$ & $\mathrm{Li}_{n} \mathrm{H}_{3}$ & $\mathrm{Li}_{n} \mathrm{H}_{4}$ & $\mathrm{Li}_{n} \mathrm{H}_{5}$ & $\mathrm{Li}_{n} \mathrm{H}_{6}$ \\
\hline 3 & 4.06 & 4.74 & 4.45 & & & & \\
\hline 4 & 4.31 & 4.17 & 5.00 & 4.38 & & & \\
\hline 5 & 4.02 & 4.27 & 4.04 & 4.90 & 4.33 & & \\
\hline 6 & 4.16 & 4.02 & 4.19 & 4.14 & & 4.50 & 4.50 \\
\hline 7 & 3.95 & 4.2 & 4.10 & 4.20 & 4.18 & & 4.50 \\
\hline 8 & 4.14 & 3.93 & 4.17 & 4.05 & 4.35 & 4.31 & \\
\hline 9 & 3.53 & 4.18 & 4.01 & 4.03 & 4.16 & & 4.15 \\
\hline 10 & 3.96 & 3.75 & 4.00 & 4.03 & 4.20 & 4.20 & \\
\hline 11 & 3.83 & 3.88 & 3.70 & 4.21 & 4.19 & & \\
\hline
\end{tabular}

Table 1 : Ionization potentials of $\mathrm{Li}_{n} \mathrm{H}_{m}$ clusters.
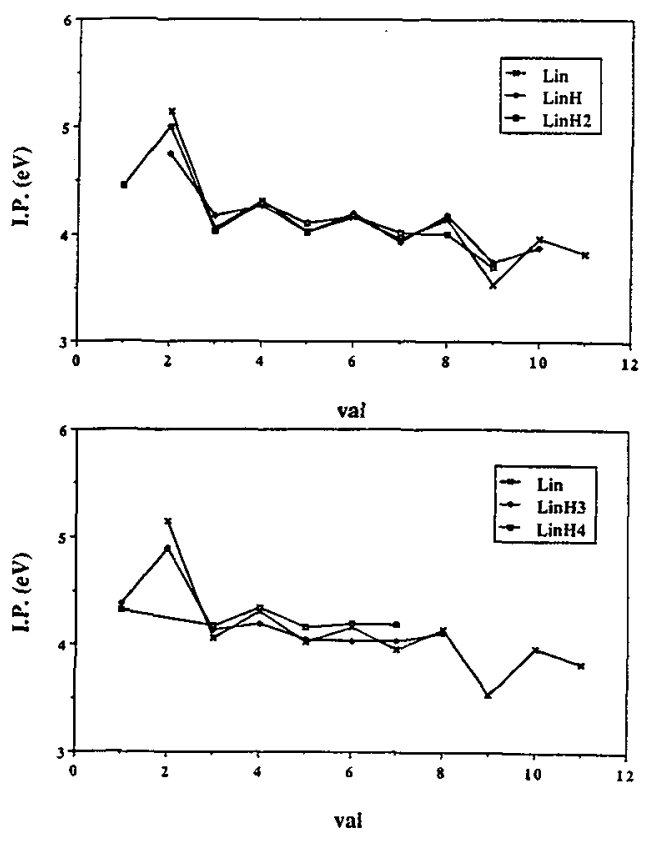

Figure 2 : Ionization potentials of $\mathrm{Li}_{n} \mathrm{H}_{m}$ clusters plotted with respect to the number $n-m$ of valence electrons.

photoionization curves of $\mathrm{Lin}_{n} \mathrm{H}_{m}$ clusters $3 \leq \mathrm{n} \leq$ $110 \leq m \leq 6$ [3], I.P.s were determinated by linear extrapolation. Ionization potentials are listed in table 1. $\mathrm{Li}_{\mathrm{n}}, \mathrm{Li}_{\mathrm{n}} \mathrm{H}$ and $\mathrm{Li}_{\mathrm{n}} \mathrm{H}_{2}$ I.P.s have already been discussed in previous papers [7,3,4]. Briefly $L i n$ I.P.s present an odd even alternation due to electronic pairing effect, significant decreases beetween $\mathrm{Li}_{2}$ and $\mathrm{Li} 3$ and $\mathrm{Li}$ \% and Lig correspond to the closing of the $1 \mathrm{~s}$ and $1 \mathrm{p}$ shells of the jellium model. The I.P.s of $\mathrm{Li}_{\mathrm{n}} \mathrm{H}$ are very closed to $\mathrm{Li}_{\mathrm{n}-1}$ I.P.s and $\mathrm{Lin}_{n} \mathrm{H}_{\mathrm{n}-2}$ I.P.s to $\mathrm{Li}_{\mathrm{n}-2}$ I.P.s (figure 2). This is explained by assuming that one -or twovalence electrons of the former $\mathrm{Li}_{\mathfrak{n}}$ cluster are localized on the $\mathrm{Li}-\mathrm{H}$ bound, and that other electrons remain free.

Evolution of the I.P.s for $\mathrm{Lin}_{n} \mathrm{H}_{3}$ and $\mathrm{Li}_{n} \mathrm{H}_{4}$ with respect to $n-m$ are plotted on figure 2 . For these clusters I.P. of $\mathrm{Li}_{\mathrm{n}} \mathrm{H}_{\mathrm{m}}$ is still very closed to $\mathrm{Li}_{\mathrm{n}}-\mathrm{m}$ I.P.. Especially the odd-even alternation is still observable. I.P.s of $\mathrm{Li}_{n} \mathrm{H}_{n-2}$ clusters are particulary high and closed to $\mathrm{Li}_{2}$ I.P., in the same way the closing of the lp shell was observed after $\mathrm{LigH}$ and $\mathrm{Li}_{10} \mathrm{H}_{2}$. In the very hydrogenated clusters, one electron is still localized by every $H$ atom and $n-m$ electrons remain delocalized. The perfect similarity between $\mathrm{Lin}_{n} \mathrm{H}_{m}$ and $L_{i n}-m$ L.P.s suggests that a bare $L i_{n-m}$ cluster survives inside the $\mathrm{Li}_{n} \mathrm{H}_{m}$ cluster. Are the $\mathrm{m} \mathrm{H}$ atoms stuck around the $\mathrm{Lin}_{\mathrm{n}}$ cluster, or is the structure of the $L i_{n}$ cluster modified with a separation between a metallic part and a insulator part ? The fact that the $L i_{n-m}$ remaining core is little disturbed by the other atoms is in favor of the second hypothesis. This phenomenon is confirmed for $\mathrm{Li}_{\mathrm{n}} \mathrm{H}_{2}$ by geometric structures determined by ab initio calculations [8].

To compare these I.P. with other mixed clusters, it is pertinent to study their evolution for a given $\mathbf{n}$ as a function of the number of hydrogen (evolution for $\mathrm{Li}_{4} \mathrm{H}_{n}$ is displayed on figure 3). As previously noticed, an odd-even alternation occurs. 
Up to $n-m=2$, these potentials are roughly equal, then an increase is observed. The I.P.s of $\mathrm{Li}_{n} \mathrm{H}_{n}$ clusters are high (we only observed $\mathrm{Li}_{6} \mathrm{H}_{6}$ ) This global trend is different from what occurs in $\mathrm{NaCl}$, $\mathrm{NaF}$ or $\mathrm{CsO}$ clusters. On $\mathrm{CsO}$, the I.P.s decrease when the number of oxygen increases, the I.P.s of $\mathrm{Cs}_{2 \mathrm{n}+1} \mathrm{O}_{\mathrm{n}}$ are particulary low [5]. In the same way, $\mathrm{Na}_{n} \mathrm{~F}_{\mathrm{n}}$ - 1 I.P.s [9] are lower than those of bare Nan clusters. Figure 3 displayed the evolution of calculated adiabatic I.P.s of $\mathrm{Na}_{4} \mathrm{~F}_{\mathrm{n}}$ clusters [10], globaly the potentials decrease whereas they increase for $\mathrm{Li}_{4} \mathrm{H}_{\mathrm{n}}$. In $\mathrm{NaCl}$ and $\mathrm{NaF}$ cuboid clusters, the low I.P. is explained by the fact that the place occupied by the only valence electron is well determined ( $F$ center) and the bound between this electron and the remaining cluster is weak. This is particulary clear in ab initio calculations of Landman [10] and Koutecky [11] for Na4F3 where the excess electron is strongly localized in the $\mathrm{F}$ vacancy. On the other hand, calculations for $\mathrm{Li}_{4} \mathrm{H}_{3}$ [12] give the same structure but the electron is more diffuse and then more bounded to the cluster.

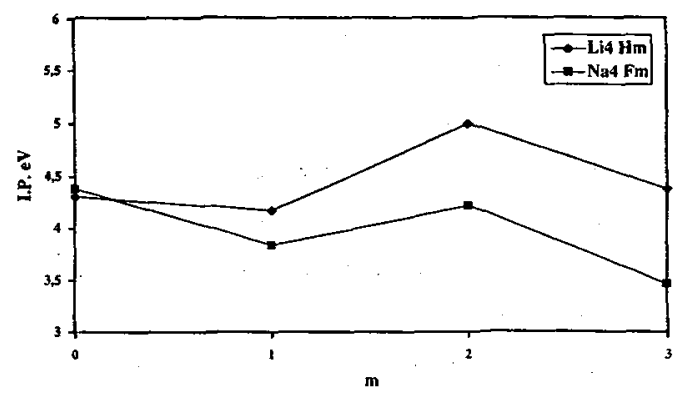

Figure 3 : evolution of measured $\mathrm{Li}_{4} \mathrm{H}_{\mathrm{m}}$ I.P.s and of calculated $\mathrm{Na}_{4} \mathrm{~F}_{\mathrm{m}}$ I.P.s [10].

\section{Conclusion}

We have measured I.P.s of $\mathrm{Li}_{n} \mathrm{H}_{m}$ clusters from bare metal to hydrogenated saturated clusters. Electronic properties are dominated by the number of valence electrons $n-m$. The very strong similarity between $\mathrm{Li}_{n} \mathrm{H}_{m}$ I.P.S and $\mathrm{Li}$-m I.P.s may be due to a segregation between a metallic part and a insulating part. Determination of absorption cross section and their comparison with ab initio calculations will be useful to conclude. Finally concerning the comparison with alkali halyde, the "F center" appears to behave differently.

\section{References}

[1] R. Pflaum, P. Pfau K. Sattler and E. Recknagel, Surf. Science 156 (1985) 165.

[2] E. C. Honea, M. L. Homer, P. Labastie and R. L. Whetten, Phys. Rev. Lett. 63 (1989) 394.

[3] B. Vezin, Ph.Dugourd, D. Rayane, P. Labastie, J. Chevaleyre and M. Broyer, Chem. Phys. Let. 206 (1993) 521.

[4] B. Vezin, Ph. Dugourd, D. Rayane, P. Labastie, C. Bordas and M. Broyer,Z. Phys. D 26 (1993) 290.

[5] H.G. Limberger and T. P. Martin, J. Chem. Phys. 90 (1989) 2979.

[6] C. Bréchignac, Ph. Cahuzac, F. Carlier, M. de Frutos, J. Leygnier and J.P. Roux, J. Chem Phys. 99 (8) (1993) 1.

[7] Ph. Dugourd, D. Rayane, P. Labastie, B. Vezin, J. Chevaleyre and M. Broyer, Chem. Phys. Let. 197 (1992) 433.

[8] V. Bonacic-Koutecky, J. Gaus, M.F. Guest, L. Cespiva and J. Koutecky,Chem. Phys. Let. 206 (1993) 528.

[9] E. C. Honea, M. L. Homer and R. L. Whetten, Phys. Rev. B 47 (1993) 7480.

[10] G. Rajagopal, R. N. Barnett and U. Landman, Phys. Rev. Lett. 67 (1991) 727.

[11] V. Bonacic-Koutecky, C. Fuchs, J. Gaus, J. Pittner and J. Koutecky, Z. Phys. D 26 (1993) 192.

[12] V. Bonacic-Koutecky, private communication. 